\title{
AS METODOLOGIAS POR PROJETO NAS SALAS DE AULAS DO CEFET- MG, DESDE O PONTO DE VISTA DOS DOCENTES DO ENSINO MÉDIO
}

\author{
Iris Maria de Souza Carvalho ${ }^{1}$ \\ Maria Aparecida Santos e Campos²
}

RESUMO: Hoje em dia, os meios utilizados para a comunicação de massa e nos sistemas de educação vêm sendo objeto de mudanças originadas a partir do desenvolvimento e difusão das tecnologias da informação e comunicação, que implementam novas estratégias no sistema educacional adaptando e integrando processos de gestão da qualidade e melhoria do ensino, vinculados aos contextos socioeconômico e cultural. Estas mudanças refletem nas tendências pedagógicas dentro das salas de aula. De acordo com o BNCC, a construção do conhecimento é um processo que envolve a participação ativa do professor e do aluno, o docente deve utilizar metodologias ativas e considerar as experiências e vivências do aluno fomentando a autonomia para assumir uma postura partícipe na construção dos saberes. Nesta perspectiva este estudo qualitativo descritivo e exploratório de corte transversal teve como objetivo verificar se os docentes do CEFET-MG, campus BH conhecem e utilizam as metodologias ativas e se incorporam a metodologia por projetos nas suas práticas docentes Amostra: 15 docentes dos cursos técnicos do CEFET. Instrumento de pesquisa: questionário Ad Hoc com perguntas fechadas, sobre metodologias ativas. Para tabulação e a análise de dados, se utilizou o programa SSPS (Statistical Program for Social Sciences)da IBM versão i.9. analisados e estão apresentados em estatística descritiva. Resultados: verificou-se que os docentes conhecem, mas, em sua maioria, não utiliza como prática docente, a metodologia de projetos. Foi identificada uma demanda para atualização dos docentes em sua formação que possa incluir a prática da interdisciplinaridade.

'Doutoranda em Educação pela Universidad Internacional Iberoamericana (UNINI-MX). Mestre em Ciência da Informação no Instituto Brasileiro de Informação Ciência e Tecnologia convênio UFRJ/FACC. Pós graduado Latu Sensu em: Indexação da Informação, Organização do Conhecimento para Recuperação da Informação e Formação de Docentes em Curso Superior. Docente d Curso de Pós Graduação em Geriatria e Gerontologia da Universidade do Estado do Rio de Janeiro. Docente do Curso de Pós Graduação em Gestão Geriátrica e Gerontológica PUC-RJ. Email:iris.desouza@doctorado.unini.edu.mx ORCID https://orcid.org/oooo-00o2-5656-o889

${ }^{2} \mathrm{PhD}$ em Educação, Universidade de Jaén. Coordenadora do Grupo de Pesquisa UNINI/BR e MEDERE. Membro do grupo de investigação HUM79o- Univ. Jaén, Grupo AL Andaluz, Universidad de Andalucia (Sevilla). Professora e diretora de tese doutoral - Universidade UNINI México no ensino superior. Professora na Associação AFIXA, Jaén, España. Mestre em Ciências da Educação, e em

Atividade Física Licenciada e Bacharel em Educação Física pela PUC-MG, Licenciada em Pedagogia pela UniBF. Especialista em Metodologia e Planejamento do ensino Superior, Educação Física Escolar, Didática e Psicologia da Educação.. Lattes:http://lattes.cnpq.br/1253652978692557 ORCID: https://orcid.org/oooo-ooor-1790-5438 e-mail:maria.santos@unini.edu.mx 
Palavras-chave. Metodologias Ativas. Trabalho por Projeto. Design Thinking. Projetos Pedagógicos.

ABSTRACT Ad Hoc: Nowadays, the means used for mass communication and in education systems have been subject to changes arising from the development and diffusion of information and communication technologies, which implement new strategies in the educational system, adapting and integrating management processes. quality and improvement of teaching, linked to the socioeconomic and cultural context. These changes reflect pedagogical trends within classrooms. According to the BNCC, the construction of knowledge is a process that involves the active participation of the teacher and the student, the teacher must use active methodologies and consider the student's experiences and experiences, fostering autonomy to take a participative stance in the construction of knowledge. In this perspective, this qualitative descriptive and exploratory cross-sectional study aimed to verify whether the teachers at CEFET-MG, BH campus know and use active methodologies and whether they incorporate the methodology by projects in their teaching practices. Sample: is teachers from technical courses at CEFET. Research instrument: questionnaire with closed questions about active methodologies. For tabulation and data analysis, the SSPS program (Statistical Program for Social Sciences) from IBM version 1.9 was used. analyzed and are presented in descriptive statistics. Results: it was found that the professors know but, for the most part, do not use the project methodology as a teaching practice. A demand was identified to update teachers in their training that could include the practice of interdisciplinarity.

Keywords. Active Methodologies. Project Work. Design Thinking. Pedagogical Projects.

\section{INTRODUÇÃO}

$\mathrm{Na}$ atualidade, a comunicação de massa, os meios utilizados e os sistemas de educação vem sendo objeto de mudanças oriundas do desenvolvimento e da difusão das novas tecnologias de informação e comunicação (TIC) que são implementadas desde a internet. De acordo com Monterrosa (2010), a expansão dos sistemas de comunicação e informação e os projetos sobre o uso das TIC's têm encontrado diversos desafios na superação de crises referentes aos programas ou softwares, que segundo o autor, define-se por "crise do software" e tem gerado inúmeros e sérios problemas para ajustes e manutenção dos programas (Monterrosa, 20ı0).

Para o autor, tais desafios têm acontecido nas esferas empresarial, tecnológica e educacional. A realidade exige mudanças estratégicas nas organizações incluindo o ambiente educacional adaptando-o às mudanças, e alianças estratégicas, os processos 
integrados e a gestão da qualidade e melhoria dos processos educacionais. Nesse aspecto deve-se destacar que "as metodologias tradicionais de ensino têm sido pouco eficientes para ajudar o aluno a pensar, refletir e criar com autonomia soluções para problemas que enfrentam" (Santos, Royer e Demizu, 2018, p. I4055). O processo educacional precisa estar vinculado à realidade dos alunos, tornando a aprendizagem como um exercício que o prepare a resolver problemas cotidianos e também para o ambiente do trabalho.

A atualidade traz consigo novas concepções em todos os âmbitos da vida, e a educação também está submetida a estas modificações, portanto, para investigar sobre as práticas docentes e o impacto das Tecnologias Digitais da Informação e Comunicação (TDIC's) no processo ensino aprendizagem faz necessário um olhar atento com o fim de pesquisar o nível de conhecimento dos docentes de ensino médio sobre as metodologias ativas e sua aplicação nas salas de aula pelos docentes. Cotidianamente, diferentes segmentos da sociedade se deparam com invenções e avanços tecnológicos, que há pouco tempo pareciam inimagináveis; o que nos pode levar a refletir se os alunos estão aptos para este mundo real e se também estão preparados para o ambiente de trabalho, para as profissões, que surgem com estas mudanças (Maia (202I p.4). Como a sociedade, a escola (incluindo aqui todos os profissionais que nela atuam), o docente e o aluno se apropriam desta realidade onde a tecnologia está presente parecendo ser de forma definitiva trazendo para o processo de aprendizagem uma forma exitosa parece ser ainda um grande desafio para todos.

A sala de aula atual já não é, ou não deveria ser, a mesma de antes, a chegada das TDIC's, vêm mudando as concepções do trabalho e processo de ensino e aprendizagem, concomitantemente a esta evolução, as metodologias sofrem ou deveriam sofrer profundas mudanças, no que diz respeito, às práticas pedagógicas no contexto escolar. Assim, os campos de conhecimento e saberes vão se ressignificando com as mudanças sociais e culturais, a partir do desenvolvimento humano, produzindo novos olhares sobre as teorias e práticas, bem como as formas de compreender as ciências. Mas a questão parece não estar restrita à utilização das novas tecnologias disponíveis. Alunos nascidos no século XXI, tendo professores formados no século XX trazem a reflexão sobre a influência das TDICs no cotidiano 
escolar e como a escola enfrenta este desafio. Ignorar a presença da tecnologia pode ser afastar a realidade do aluno ao seu processo de aprendizagem. Seu uso indiscriminado pode não resultar em qualidade no ensino. Mas estes autores afirmam que ao ser usada de forma adequada vem ser uma grande aliada do "profissional da educação" proporcionando tanto ao professor quanto ao aluno a exploração de mundos extra muros escolares. (Deschamps \& Calegari, 2015). Dessa forma, para que uma aprendizagem possa preparar o aluno para a realidade do século XXI, considera-se necessária uma mudança de postura do professor e das instituições, que estão submergidas no ensino de cunho tradicional, onde o professor assume o papel de ator principal, considerando o estudante como um mero receptor do processo.

O aluno atual já chega à escola com acúmulo de saberes muitas vezes ignorado pelas práticas docentes tradicionais onde o professor é considerado detentor do conhecimento. Segundo os autores, ( Santos, Royer e Demizu, 2018, p. I4055), ainda que os alunos possuam tal conhecimento não conseguem aplicar os saberes na sua vida cotidiana. Neste sentido, as metodologias ativas, de acordo com Valente (2018, p. 26), "são entendidas como práticas alternativas ao ensino tradicional". Em vez do ensino baseado na transmissão da informação: “(...) na metodologia ativa o aluno assume uma postura mais participativa (...)”. Desta forma professor e aluno constroem juntos o conhecimento tornando a aprendizagem significativa. Em suas investigações sobre metodologias ativas, Valente (2018, p. 27) verificou diferentes práticas pedagógicas que trazem os alunos como protagonistas do conhecimento e o professor como mediador: “(...) envolvendo-o na aprendizagem por descoberta, investigação ou resolução de problemas". Neste contexto metodologias ativas pode ser definida como: "um conjunto de procedimentos didáticos centrados no aluno, expressos pelos métodos e técnicas de ensino com forte caráter colaborativo e participativo" onde o docente assume o papel de mediador, atento aos “objetivos de ensino" tornando as experiências em aprendizagem significativa (SENAC, 2018, p.9).

Esta ideia que questiona a postura do aluno como um simples receptor de informação e a do professor como detentor do saber, no processo de aprendizagem, 
não é tão recente. A ideia deste recurso pedagógico pode ser notada ao final do século XIX quando John Dewey em I897 já a concebia (Moura \& Barbosa, 2017). Em sua abordagem teórica Dewey (1859-1952) menciona a "artificialidade" que está relacionada ao que se aprende na escola por estar distante da "realidade que a matéria de suas experiências vitais”. Afirma que “...a experiência ... dos estudantes não adquire o enriquecimento que poderia ter; não é fecundada pelos estudos escolares" (Dewey, 1979, p.177). Para este autor a aprendizagem é facilitada quando se aproxima da realidade, das experiências do aluno. Neste sentido, este trabalho identifica um elo que traz Dewey ao princípio das metodologias ativas, particularmente à metodologia por projetos, que também possui como princípio que: o conteúdo a ser assimilado esteja baseado na aprendizagem pela experiência do aluno, que tenha significado para ele.

Moran (2013, p.04), destaca que as metodologias ativas necessitam de uma transformação pessoal e coletiva, considerando todos os atores do processo de ensino e aprendizagem, que inclui uma outra percepção de todos os segmentos da Escola e envolve um universo amplo de pessoas que podem participar desta mudança. $\mathrm{O}$ autor considera que não é fácil a mudança de "paradigmas mentais consolidados” onde o docente passa para a posição de mediador no processo de aprendizagem onde a participação do aluno aumenta com fortalecimento da utilização das tecnologias digitais. Absorver e acompanhar todas estas mudanças pode não ser simultâneo para todos os participantes deste processo, podendo exigir uma atenção maior dos gestores possibilitando que os que apresentarem maiores dificuldades possam vencê-las. Promover troca de experiências, realizar oficinas, dentre outras podem proporcionar maior intercâmbio entre todos os envolvidos.

Moran (2013), salienta que o trabalho com metodologias ativas, no sentido de redesenhar os espaços escolares com repertórios diversificados que propiciam melhorar a conectividade entre os envolvidos. E destaca, que as abordagens técnicas devem ser trabalhadas em diferentes dimensões, onde o aluno e o professor atuam ativamente na construção do saber. $O$ autor ressalta que existem diferentes possibilidades no aprender onde caminhos e tempos podem ser diferentes mostrando que existe um "desafio complexo" na personalização da aprendizagem para 
atendimento às diferentes necessidades de cada estudante considerando o grande número de alunos que o docente acompanha.

As metodologias ativas abarcam um grupo de técnicas e tem como uma de suas características o papel do educador de "ativar seus alunos" personalizando a aprendizagem. O termo no plural "metodologias ativas" é um indicador deste universo amplo. Podemos citar aqui algumas destas técnicas: sala de aula invertida, gamificação, aprendizagem baseada em problemas, tutoria entre pares, dentre outras (Beck, 20I8, p.I-2). Pode-se afirmar que existem várias modalidades de ensino baseadas nos princípios das metodologias ativas. Este trabalho aborda a metodologia de trabalho por projetos pois identifica nela princípios e práticas que podem ser aplicados com o ambiente educacional no qual este estudo se desenvolve.

Necessário observar que "novas metodologias de aprendizagem" podem não ser tão novas assim. De acordo com Bacich \& Holanda (2019) projetos já fazem parte do universo educacional há algum tempo, não muito explícito a partir de quando, onde diferentes tipos objetivam integrar "conteùdos curriculares" tendo como exemplos as feiras literárias, mostras de ciências. Estes projetos trazem temas que não constam do currículo mas de alguma forma interessa trazer para discussão no ambiente escolar. Os autores trazem a observação da dificuldade em definir o que é um projeto, afirmando que não há uma só definição. Para eles, a principal diferença entre "projetos temáticos" citados neste parágrafo e aprendizagem baseada em projetos é que esta é uma metodologia ativa e que "utiliza projetos como foco central de ensino". A aprendizagem baseada em projetos tem como característica surgir de um problema real que envolve investigação promovendo trabalho em grupo, a interdisciplinaridade, a criatividade e o pensamento crítico.

Assim, a partir das metodologias ativas inclui-se aprendizagem baseada em problemas e projetos, que consideram problemas reais interligando as áreas do conhecimento (característica da interdisciplinaridade que será abordada mais adiante) e dos conhecimentos prévios dos alunos. A proposta de inclusão da técnica de trabalho por projetos na prática docente objetiva considerar a experiência do aluno e proporcionar formação de competências e habilidades numa participação e aprendizagem ativas, onde os alunos assumem como protagonistas construindo seu 
conhecimento num processo em que o docente atua como mediador. O trabalho por projetos propõe transformar o modelo tradicional, onde o professor expõe verbalmente o conteúdo, para um ambiente participativo onde o conhecimento é fruto de uma construção que tem a participação tanto dos alunos quanto do professor.

Importante observar que esta prática pedagógica, trabalho por projetos, possibilita o protagonismo do aluno através dos diálogos e da potencialização da criatividade, nos diferentes espaços escolares, mesclando e conectando os diferentes atores. O que enfatiza Moura e Barbosa (2017, p. 20), que: "procedimento pedagógico desenvolvido tendo por base uma metodologia conhecida por "método de projetos", metodologia de projetos" ou "pedagogia de projetos". Neste contexto identifica-se que o conhecimento é construído com a significativa participação dos alunos que realizam suas atividades orientados pelos docentes onde se possibilita, através da aprendizagem significativa dentro do contexto real do aluno, a formação de habilidades e a construção do conhecimento.

Bender (2015, p. 9), utiliza a expressão “aprendizagem baseada em projetos” definindo-a como "um modelo de ensino que consiste em permitir que os alunos confrontam as questões e os problemas do mundo real que considerem significativos, determinando como abordá-los e, então, agindo de forma cooperativa em busca de soluções". O autor considera como uma das "melhores práticas" que a educação pode utilizar atualmente, se fundamenta na concepção de que a aprendizagem está relacionada aos interesses do aluno que é envolvido em tarefas que tenham conexão com sua realidade de vida. Esta conexão do processo de aprendizagem com situações próximas à realidade permite tanto ao aluno como às comunidades intra e extra escolar se beneficiarem dos resultados obtidos por todos.

Portanto, ao estimular o aluno, de forma que desenvolva suas capacidades para resolver problemas e com interdisciplinaridade é necessário que o professor lhe situe em meio deste processo e que permita trabalhar com os desafios da situação problema para que aprenda todos os passos até chegar a solução. Observa-se aqui a importância da atuação do docente como mediador conduzindo o processo de aprendizagem, que deve partir dos interesses dos alunos, da sua realidade e que são 
alinhados aos objetivos curriculares mais flexíveis (Moran, 2018). Estas oportunidades de aprendizagem lhe motivarão e permitirá que o conhecimento se interiorize desde sua prática e experiência, o que segundo Pasquelleto et al.(2017), auxiliará na resolução do problema real”.

Neste sentido Deprá, (2019, p. 2) destaca que "o papel do educador...é o de estimular, observar, mediar, criando situações de aprendizagem significativa”. $O$ trabalho por projetos pode trazer para o grupo a resolução, em princípio desconhecida, de um problema emergente e importante. $O$ papel assumido pelo professor nas metodologias ativas é o de mentor conduzindo o aluno no seu crescimento no processo de aprendizagem. Santos, Royer e Demizu, (2018, p. 14056) ressaltam que "a ação docente necessita obter horizontes mais amplos ... pois o docente precisa buscar novas metodologias de ensino que proponham a reflexão, a pesquisa e a investigação sobre pressupostos teóricos e práticos das abordagens do ensino e da aprendizagem”. Portanto, a atuação docente necessita modificar-se de uma postura autoritária onde é o detentor do saber, observando esta realidade que exige mudanças nas suas práticas cotidianas adotando uma visão holística do ensino tornando-o mais abrangente e próximo ao mundo real.

As arquiteturas pedagógicas serão mais flexíveis, abertas, híbridas, personalizadas, ativas e colaborativas, com diferentes combinações, arranjos, adaptações num país com realidades muito desiguais. Estamos começando a sair do modelo mental de identificar aprendizagem com um professor e 40 alunos em uma sala presencial. O ideal é o equilíbrio entre a personalização (mais escolhas do aluno, mais autonomia) com a aprendizagem colaborativa (aprendizagem ativa, entre pares, por projetos), a tutoria/mentoria, avaliação formativa, oferecendo as melhores condições de aprendizagem em tempo real (sala de aula, plataformas online, espaços profissionais) e de forma assíncrona (com itinerários e atividades mais individualizados).

No uso das metodologias ativas as teorias de aprendizagem se centram nos alunos e adotam estratégias didáticas que lhes predisponham uma participação ativa do processo construindo seu próprio saber. De acordo com Silva \& Maturana (2017), 
as teorias $\mathrm{da}$ aprendizagem centradas no aluno promovem a utilização das metodologias ativas nas estratégias didáticas à disposição dos docentes, que se consideram importantes ferramentas usadas na transformação da docência e do processo de ensino aprendizagem.

Desta forma percebe-se que existe um movimento onde as metodologias promovem incluir o aluno para a construção participativa no processo de aprendizagem. Em paralelo algumas discussões abordam a necessidade de adoção de um trabalho de maneira colaborativa entre os educadores. O olhar para empresas de sucesso percebe que a colaboração entre todos os envolvidos no trabalho é fator significativo na geração de bons resultados (Garbin; Amaral, 2013).

Neste sentido pode ser observado que ao longo do percurso outras áreas do conhecimento contribuem para mudanças significativas na educação. Neste aspecto este trabalho inclui o design thinking considerado como uma "ferramenta estratégica" inicialmente utilizada por grandes empresas e, que ao ser "aplicado ao contexto educacional ele pode favorecer o funcionamento dos processos internos de escolas e outras instituições de ensino”. (Escolas Disruptivas, s.d., p. 5). É definido por (Martins Filho et al, 2015, p. 587) como "um processo para a resolução de problemas complexos, desenvolvido colaborativamente e centrado no ser humano". Sua proximidade ao processo ensino-aprendizagem está relacionada à visão" dessa abordagem que se inspira na coletividade e na percepção das pessoas sobre um determinado assunto, nada mais justo do que utilizar o design thinking na educação e tornar esse conceito ainda mais interessante". Sua busca por soluções de problemas, que permitem agregar uma variedade de pessoas que podem estar interessadas e serão impactadas por estas soluções, têm estreita similaridade com a metodologia por projetos e identificando-se que pode haver uma integração entre ambos.

Outro aspecto referido por Brown \& Katz (2019, p. 76, tradução nossa) é que "sementes do design thinking fazem um contínuo movimento entre o processo divergente e o processo convergente, por um lado e, entre o sintético e o analítico, por outro lado". Para estes autores como no trabalho de um jardineiro o solo para o desenvolvimento deste processo precisa ser preparado. $\mathrm{Na}$ utilização desta ferramenta, design thinking, no processo educacional cabe ao professor como 
mediador preparar o ambiente de aprendizagem como uma experiência exitosa no cenário escolar. Este aspecto identificado no design thinking de "contínuo movimento" onde alinha processos opostos apresenta similaridade com o trabalho por projetos que dentro de seu desenvolvimento vai gerando novos projetos.

De acordo com Bacich (2018) o alinhamento do indivíduo ao seu entorno propicia maiores possibilidades da percepção do todo, o que lhe permite indagar sobre os aspectos que influenciam na sua própria aprendizagem descobrindo uma nova forma de aprender ao utilizar o desenho do pensamento, portanto o design thinking (DT) ao estimular a dialética ao aluno partindo de suas indagações se aproxima da criação de projetos reais. Design thinking potencializa o questionamento dos alunos induzindo-lhes a não aceitar a informação única e simplesmente, com técnicas que lhes estimulam a treinar a mente para observar os distintos pontos de vista do problema, a ser pacientes, e tolerantes ao escutar, resolver inconvenientes. Tornando-se observadores e pensadores organizados e com potencial do trabalho em equipe, criando de ideias inovadoras, agentes das mudanças onde participam ativamente.

Cabe aqui ressaltar que para que todas estas mudanças possam ser exitosas o docente tem atuação de extrema importância. Há necessidade de mudanças tanto na sua forma de ensinar quanto na sua disposição para aprender. A observação do cotidiano escolar implementa questões de transformações no trabalho e funções do docente. Estas transformações precisam incluir toda a comunidade escolar. Cabe observar que a função do coordenador pedagógico precisa estar atenta à formação dos docentes não se limitando às múltiplas funções burocráticas que o cargo impõe.(MARIHAMA; ZANESCO, 202I). Nestes tempos atuais onde ocorrem rápidas mudanças no acesso à informação e produção de conhecimento se torna fundamental investir na formação docente. $\mathrm{Na}$ sua formação continuada o professor tem possibilidades de adquirir novos conhecimentos, o que lhe permite aprimorar práticas pedagógicas, oferecendo tanto ao docente como ao aluno a oportunidade na construção de novos saberes (Yavorski \& Santos e Campos, 2019). 


\section{METODOLOGIA}

O desenvolvimento da pesquisa foi elaborado em algumas etapas. A partir da seleção do local de pesquisa e quais participantes seriam ou não incluídos, o pesquisador buscou conhecer o ambiente da pesquisa, através de documentos disponibilizados na página web da Instituição. Paralelamente foi necessário reunir literatura sobre os diferentes temas que a pesquisa inclui o que é um trabalho infindável devido à necessária e permanente atualização dos temas envolvidos.

Esta busca por documentos da Instituição, objeto da pesquisa, trouxe o universo documental expressivo onde foi encontrado material identificador de suas políticas e diretrizes educacionais. Neste material, para o desenvolvimento da pesquisa, considerou-se importante inicialmente identificar, através da seleção de um conjunto de palavras que foram denominadas "eixos de referência" que determinaram o caminho para a construção do questionário, aqui chamado de instrumento de pesquisa. É um questionário do tipo ad hoc, pois assim são chamadas estas ferramentas elaboradas exclusivamente para uma determinada pesquisa. Este questionário foi construído partindo das categorias identificadas como "eixos de referência". Esta seleção foi elaborada para verificar a relação entre: o conjunto de respostas docentes ao questionário aplicado, o conteúdo dos documentos da Instituição e as características principais das metodologias ativas por projeto, buscando assim uma linha relacional entre estes importantes elementos da pesquisa. Estas palavras foram extraídas observando sua ocorrência na literatura especializada e foram consideradas expressivas para o conjunto dos elementos principais deste trabalho: as metodologias ativas, a demanda dos docentes e os documentos. $\mathrm{O}$ objetivo é identificar na literatura palavras-chave ou termos significativos que caracterizam estes elementos promovendo uma leitura transversal entre eles..

Este é um estudo qualitativo descritivo e exploratório de corte transversal. Participantes: amostra probabilística composta por 15 professores do ensino médio tecnológico, tendo como critérios de exclusão: não estar atuando como docente no ensino médio do CEFET-MG. Foi considerado como critério de inclusão: ser docente atuando no ensino técnico. 
Instrumento de avaliação - Foi elaborado um questionário com 22 perguntas com variada quantidade de opções para respostas (estas opções variam numa escala de 2 à I2). Idealizado pelo pesquisador foi validado, numa primeira etapa, por especialistas selecionados na instituição de pesquisa tendo como quesito principal a experiência em trabalho com este tipo de instrumento. Foram observadas as recomendações destes especialistas ajustando o questionário à elas. Numa segunda etapa foi aplicado a um grupo de professores para que fosse observado sua efetiva aplicabilidade. Nesta ferramenta ad hoc as questões foram elaboradas para conhecer: identificação dos entrevistados, situação da atuação docente, atualização profissional, nível de conhecimento e utilização em relação à metodologias ativas, metodologias de projeto e design thinking.

Análise de dados: foi feita por meio de análise de conteúdo que, segundo Bardin (2009, p. 20) "é uma técnica de investigação que tem por finalidade a descrição objetiva, sistemática e quantitativa do conteúdo manifesto da comunicação”.

Local da pesquisa: $O$ Centro Federal de Educação Tecnológica, subordinado diretamente ao Ministério da Educação no Brasil, é composto de um conjunto de institutos brasileiros que oferecem cursos nos níveis médio, técnico e superior. Seu perfil atual vem sendo definido ao longo da história político econômica do país: desde a necessidade de formação de mão de obra para o ensino profissional, passando pela rede de estabelecimentos de ensino industrial ampliando sua atuação na formação de docentes para o ensino técnico e superior. Também pode ser definido como "modelo de instituição educacional autárquica federal, vinculada ao Ministério da Educação (MEC), com autonomia administrativa, patrimonial, financeira, didática, técnica e disciplinar, caracterizando-se por ministrar cursos técnicos nas áreas industrial e de serviços” (Menezes, 2002, p.ı).

\section{RESULTADOS}

Para a apresentação dos resultados buscou-se na literatura um embasamento teórico objetivando a formalidade científica para tal. Pereira (2013) pontua, dentre várias recomendações, que, primeiramente, devem ser apresentadas as características principais dos entrevistados. Outro ponto ressaltado pelo autor é que a emissão de 
opinião pelo pesquisador deve fazer parte da discussão, na apresentação dos resultados deve somente constar uma breve menção a cada achado incluindo os dados estatísticos.

Observando que o objetivo principal deste trabalho é verificar se os docentes do CEFET- MG conhecem e utilizam as metodologias ativas e se incorporam a metodologia por projetos nas suas práticas docentes e a partir do instrumento de pesquisa aplicado foram obtidos os resultados apresentados a seguir. Para atingir este objetivo foram selecionados is docentes do ensino técnico atuantes em sala de aula.

Os dados sociodemográficos desta pesquisa com os professores participantes, identificou-se que: (25\%) deles são do sexo feminino e (75\%) masculino, predominando a faixa etária entre os $4 \mathrm{I}^{\mathrm{I}}-50$ anos com $(43,8 \%)$, e entre $30-40$ anos $(25 \%)$, mais de 50

anos $(31,3 \%)$. Pode ser verificado aqui a predominância de faixa etária onde se espera experiência profissional. Para relacionar este dado com o tempo de atuação na área estudada foi elaborada a pergunta cujo gráfico abaixo consolida as respostas.

Figura n.I Tempos de atuação no Ensino Médio

3. Há quanto tempo atua na Área de Ensino Médio Técnico?

16 respostas

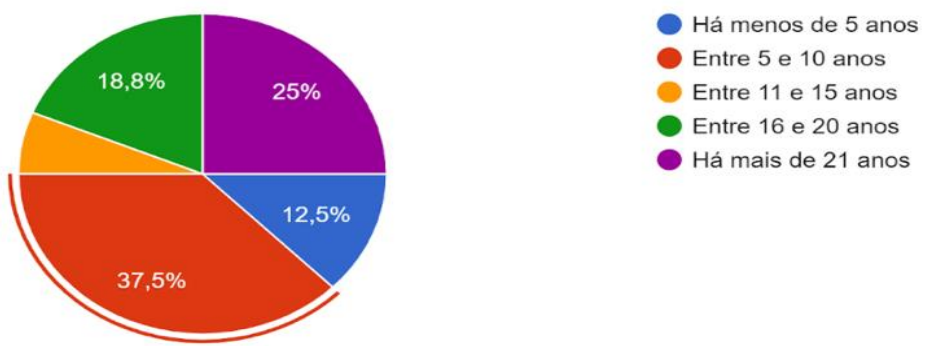

Fonte: (Do próprio autor)

Em relação ao tempo de serviço no ensino médio técnico, verificou-se que a maioria, como pode ser observado na figura I, (37\%) já atua na docência há mais de 5 anos, o que lhes confere um certo grau de experiência. Por outro lado (25\%) dos docentes já estão com mais de 2i anos de carreira configurando experiência na profissão. 
Um outro interesse do pesquisador foi a questão da capacitação específica, pela Instituição, para os docentes entrevistados. Como pode ser observado no gráfico abaixo, uma minoria assinalou que é frequente esta capacitação e que as respostas obtidas apresentaram divergência; onde 31, assinala raramente e $37 \%$ às vezes isso acontece.

10. O CEFET/MG promove capacitação pedagógica para os docentes?

16 respostas

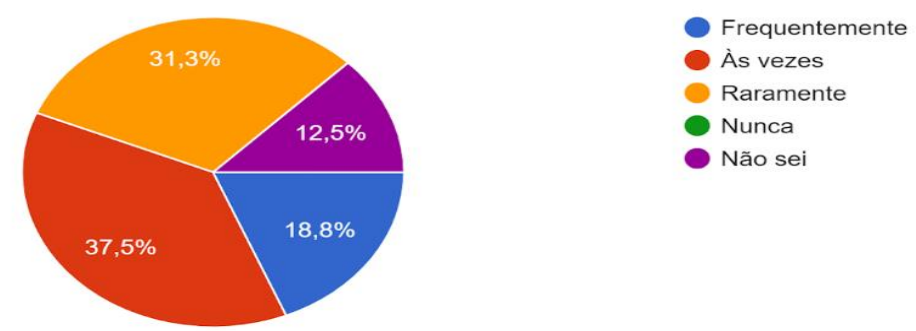

No entanto, os resultados demonstram que a grande maioria dos professores conhece a metodologia por projetos na prática mas somente $33 \%$ a utilizam. Traduzidos em termos quantitativos tem-se que 12 professores, conhecem a metodologia por projetos na prática docente, somente 5 aplicam com frequência. Neste sentido Brognoli \& Teixeira assinalam que a utilização da prática pedagógica por projetos está alinhada com as orientações pedagógicas vigentes no país, os Parâmetros Curriculares Nacionais, através das quais os alunos poderão aprender princípios que serão utilizados além de seu "ambiente escolar".

17. Você conhece a metodologia por projetos?

16 respostas

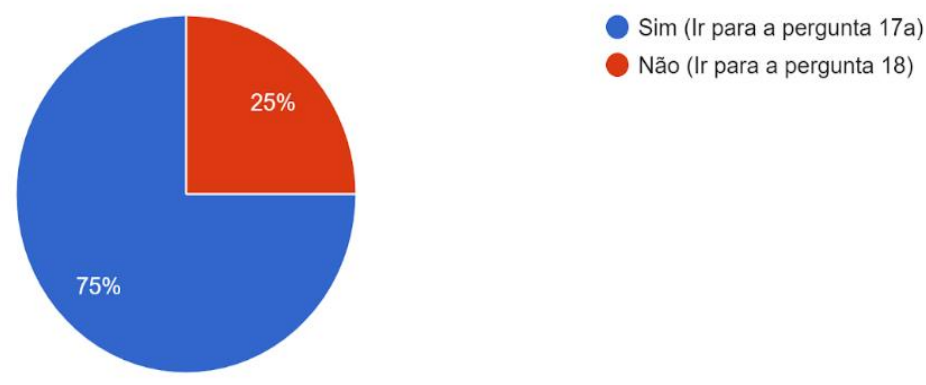


Ao analisar as respostas dos docentes da tabela n. I, abaixo, identifica-se que 33\% ( 5) dos professores, tem formação específica para a docência, significa que 33\%, que na sua maioria, $67 \%$ dos docentes que atuam no ensino médio tecnológico, não são licenciados, segundo Yavorski e Santos e Campos (2021, p. 25), o processo de aprendizagem necessita de profissionais preparados para enfrentar $t$ odos os desafios da educação, sendo assim, a formação deste profissional torna-se item básico e importante.(...) As dificuldades apresentadas pelos alunos podem ser ultrapassadas a partir da utilização de técnicas inovadoras, que motivem os alunos na busca de conhecimento.

Tabela n.I- Variáveis sobre docência e metodologias empregadas nas salas de aula

\begin{tabular}{|c|c|c|c|c|c|c|c|}
\hline $\begin{array}{l}\text { Respostas } \\
\text { Variáveis }\end{array}$ & $\mathrm{Sim}$ & Não & Nunca & $\begin{array}{c}\text { As } \\
\text { vezes }\end{array}$ & $\begin{array}{l}\text { Não } \\
\text { sei }\end{array}$ & Raramente & Frequentemente \\
\hline formação específica para & 5 & 10 & & & & & \\
\hline & & 7 & 3 & 3 & 2 & & \\
\hline trabalho docente interdisciplinar & & & & 6 & & 6 & 2 \\
\hline $\begin{array}{l}\text { integração entre as Areas } \\
\text { conhece a metodologia por } \\
\text { projetos }\end{array}$ & & 3 & 1 & 6 & 1 & 5 & 2 \\
\hline $\begin{array}{l}\text { utiliza a metodologia por } \\
\text { projetos em sua prática docente }\end{array}$ & & 2 & & 4 & & 1 & 5 \\
\hline
\end{tabular}

Um outro aspecto a ser observado é a conexão necessária entre as disciplinas ministradas no Ensino Técnico sobretudo entre àquelas que estão direcionadas para a formação profissional discente. Ao abordarem a "adoção da interdisciplinaridade" Santos, Nunes e Viana (2017), enfatizam que "a necessidade de eliminar fronteiras curriculares ...” permitindo aos alunos “... perceberem que um único conteúdo pode ser essencial para o aprendizado de diversas disciplinas ...” sendo que esta prática acompanha sua formação profissional. Neste contexto o trabalho por projetos está alinhado por uma integração entre disciplinas onde trabalha com a identidade entre estas "sendo que esta permeabilidade amplia e articula diferentes áreas de conhecimento, construindo nos estudantes uma noção mais global sobre os conceitos investigados e gerando trocas de saberes entre as disciplinas”. (Mendes Filho, 2016, p. 50). 
Na tabela abaixo, n. 2, buscou-se correlacionar a área de atuação do docenterespondente com sua capacitação específica para docência. (*respondeu 2 vezes) A informação sobre formação acadêmica foi obtida através de consulta à plataforma Lattes (Plataforma Lattes (cnpq.br).

Tabela 2 - Professor, área de ensino formação,

\begin{tabular}{|c|c|c|c|}
\hline Docentes & Área de Ensino & Formação Docente & Formação Acadêmica $^{\text {*ᄎ }}$ \\
\hline Professor 1 & $\begin{array}{l}\text { Informática } \\
\text { Rede de } \\
\text { Computadores }\end{array}$ & $\begin{array}{c}\text { Formação Pedagógica de } \\
\text { Professores (Nivel Graduação) }\end{array}$ & Ciências da Computação \\
\hline Professor 2 & $\begin{array}{l}\text { Informática } \\
\text { Rede de } \\
\text { Computadores }\end{array}$ & Não & $\begin{array}{l}\text { Graduação em } \\
\text { Matemática }\end{array}$ \\
\hline Professor 3 & $\begin{array}{c}\text { Rede de } \\
\text { Computadores }\end{array}$ & Não & \\
\hline Professor 4 & Informática & Não & Engenharia Elétrica \\
\hline Professor 5 & $\begin{array}{l}\text { Informática } \\
\text { Rede de } \\
\text { Computadores }\end{array}$ & Não & Engenharia Elétrica \\
\hline Professor 6 & $\begin{array}{l}\text { Equipamentos } \\
\text { biomédicos }\end{array}$ & $\begin{array}{c}\text { Sim (docente em disciplinas } \\
\text { técnicas) }\end{array}$ & \\
\hline $\begin{array}{l}\text { Professor } \\
7^{*}\end{array}$ & $\begin{array}{l}\text { Equipamentos } \\
\text { biomédicos }\end{array}$ & Não & \\
\hline Professor 8 & $\begin{array}{l}\text { Equipamentos } \\
\text { biomédicos }\end{array}$ & Em branco & \\
\hline Professor 9 & $\begin{array}{c}\text { Rede de } \\
\text { Computadores }\end{array}$ & Licenciatura em Matemática & $\begin{array}{c}\text { Licenciatura em } \\
\text { Matemática }\end{array}$ \\
\hline $\begin{array}{l}\text { Professor } \\
10\end{array}$ & $\begin{array}{l}\text { Informática } \\
\text { Rede de } \\
\text { Computadores }\end{array}$ & Não & Ciência da Computação \\
\hline $\begin{array}{l}\text { Professor } \\
11\end{array}$ & Eletrotécnica & Não & \\
\hline $\begin{array}{l}\text { Professor } \\
12\end{array}$ & Eletrônica & Não & \\
\hline $\begin{array}{l}\text { Professor } \\
13\end{array}$ & Eletrônica & Não & Engenharia Eletrônica \\
\hline $\begin{array}{l}\text { Professor } \\
14\end{array}$ & Eletrônica & Sim, Física & $\begin{array}{c}\text { Licenciatura em } \\
\text { Matemática e Física }\end{array}$ \\
\hline $\begin{array}{l}\text { Professor } \\
15\end{array}$ & Eletrônica & Não & Engenharia Elétrica \\
\hline
\end{tabular}

A partir destes dados expostos na tabela 3 foi verificada a necessidade de dar destaque ao quantitativo da área de ensino do docente respondente para maior conhecimento do universo pesquisado. Desta forma seguem estes dados. 
Tabela 3 - Quantitativo de respondentes por área de ensino. "Fonte: própria".

\begin{tabular}{l|c}
\hline \multicolumn{1}{c|}{ Area de ensino } & $\mathbf{N}^{\circ}$ de docentes respondentes \\
\hline Informática Rede de Computadores & 4 \\
Equipamentos biomédicos & 3 \\
Eletrotécnica & 1 \\
Eletrônica & 4 \\
Informática & 1 \\
Rede de computadores & 2 \\
\hline \multicolumn{1}{c}{ Total } & 15 respondentes \\
\hline \multicolumn{2}{c}{}
\end{tabular}

\section{DISCUSSÃO}

O objetivo principal desta investigação foi verificar se os docentes do CEFET-MG conheciam e utilizavam a metodologia por projetos em suas práticas docentes. Durante a leitura das respostas ao instrumento de pesquisa e, ao elaborar os quadros acima, foi observado que os docentes conhecem a metodologia mas não há uma concentração significativa nas respostas que confirmem esta utilização. Pode ser considerado pertinente a instituição planejar em incluir esta metodologia como prática docente. Desta forma a capacitação docente permanente pode vir a contribuir para esta inclusão.

Quanto ao quesito “capacitação na Instituição”, embora também haja uma dispersão nas respostas, percebe-se que não há ocorrência positiva desta política na Instituição estudada. Neste sentido surge a questão se há necessidade de uma sugestão de implementação de uma prática de capacitação docente? Esta necessidade se apoia no documento Base Nacional Comum Curricular, BNCC ( Ministério da Educação, 2018, p.17) onde ... " manter processos permanentes de formação docente que possibilitem contínuo aperfeiçoamento dos processos de ensino e aprendizagem”. Neste sentido considera-se pertinente a inclusão de indicação de capacitação docente proporcionando acesso à maior variedade de práticas pedagógicas.

Esta observação pode ser estendida à tabela 4, onde se pretendeu entender a relação entre a área onde o docente atua, se possui formação para docência e sua formação acadêmica. Esta tabela apresenta uma significativa variedade na formação 
acadêmica e a pouca ocorrência de formação docente específica entre os professores. Pode ser notado que o docente além de não possuir formação específica para o curso que ministra aulas. As respostas analisadas mostram ocorrência maior entre docentes respondentes das áreas de ensino de "Informática Rede de Computadores" e "Eletrônica”. Surge aqui a questão se não há uma exigência e/ou um estímulo para que professores da área tecnológica possuam formação específica para a disciplina que ministram aula.

Observou-se, uma dispersão com similaridade nas respostas dos quesitos "trabalho docente interdisciplinar" e "integração entre as Áreas" o que mostra, em princípio, que não há um trabalho integrado entre as disciplinas. Considerando que o Ensino médio técnico tem, de acordo com Ramos (2014, p.218), "principal desafio da formação integrada de trabalhadores" considera-se pertinente que esta integração seja iniciada na formação do educando promovida pelos docentes e " admitida essa forma como uma necessidade e uma possibilidade, ele é, antes, uma concepção de formação humana que pode se estruturar no interior da escola por mediações pedagógicas próprias”. Neste sentido, se aplicam as metodologias ativas e, em particular, o desenvolvimento do trabalho por projetos como possibilidade e alternativa para promoção da interdisciplinaridade com integração entre as áreas.

\section{CONSIDERAÇÕES FINAIS}

Entende-se que a educação evolui segundo as mudanças em todos os âmbitos sociais que produz fatores modificadores dos comportamentos da sociedade, nessa tessitura, a escola deve avançar e adaptar-se às práticas pedagógicas no sentido de acompanhar a evolução social, tecnológica e educacional que vão sendo implantadas no sistema de ensino em todo mundo. Assim recomenda-se que os professores do ensino técnico somem-se a estes avanços metodológicos que estão pensados para melhorar o índice de aprendizagens dos alunos. E nesse aspecto, contribua no desenvolvimento social, político e econômico formando profissionais aptos a desenvolverem-se nos mais diversos contextos que se apresentarem em sua vida laboral 


\section{REFERÊNCIAS BIBLIOGRÁFICAS}

BACICH, Lilian; HOLANDA, Leandro. Aprendizagem baseada em projetos: desafios da sala de aula em tempos de BNCC. Revista Educatrix, 8 (I4), 2018. Disponível em: https://lilianbacich.com/2019/or/16/aprendizagem-baseada-emprojetos-desafios-da-sala-de-aula-em-tempos-de-bncc/ Acesso em: 05/Io/202I.

BACICH, Lilian. Por que metodologias ativas na educação. In: SZUPARITS, Bárbara (org.). Crescer em rede: metodologias ativas. São Paulo: Instituto Crescer, 2018. p. 17-19.

BARDIN, Lawrence. Análise de conteúdo. Lisboa: edições 70, 2009.

BECK, Caio. Metodologias Ativas: conceito e aplicação. Disponível em: https://andragogiabrasil.com.br/metodologias-ativas/ Acesso em: 30/o9/202I.

BENDER, William N. Aprendizagem baseada em projetos: educação diferenciada para o século XXI. Porto Alegre: Penso Editora, 2015.

BRASIL. MINISTÉRIO DE EDUCAÇÃO. Base nacional comum curricular. Brasília-DF: Ministério da Educação, Secretaria de Educação Básica, 2018.

BROGNOLI, Ângela Faria; TEIXEIRA, Fátima Regina. A prática pedagógica de projetos no ensino técnico integrado do IF-SC-Campus Florianópolis. Caderno de Publicações Acadêmicas, I(I), o8-08, 2009.

BROWN, Tim; KATZ, Barry. Change by design: how design thinking transforms organizations and inspires innovation. New York, NY: HarperBusiness, 2019. 294 p.

DEPRA, Fernanda de Souza Reis. A pedagogia de projetos no processo ensino aprendizagem da educação infantil. Disponível em: https://www.sitededicas.com.br/art_pedagogia_projetos.htm Acesso em 23/10/2021.

DESCHAMPS, Eduardo; CALEGARI, Diego. Introdução. In: TEIXEIRA, Clarissa Stefani; EHLERS, Ana Cristina da Silva Tavares; SOUZA, Marcio Vieira de 
(orgs.). Educação fora da caixa: tendência para a educação do século XXI. Florianópolis, SC: Bookess, 2015. 324p.

DEWEY, John. Democracia e educação. São Paulo: Nacional, 1979.

MARTINS, César. Guia completo do design thinking para a educação. Disponível em: [E-book] Guia completo do Design Thinking para a educação | Escolas Disruptivas Acesso em: 25/03/2021.

GARBIN, Monica Cristina; AMARAL, Sérgio Ferreira do. Design thinking: a colaboração como mola propulsora da inovação na educação. Revista InovaEduc| (2), ago. 2013. Disponível em: Revista InovaEduc| Lantec - Laboratório de Inovação Tecnológica Aplicada na Educação (unicamp.br) Acesso em: 02/ro/202I.

LAMIM-GUEDES, Valdir. Metodologias ativas: diferentes abordagens e suas aplicações. São Paulo: Editora Na Raiz, 2021. II8 p.

MARIHAMA, Diego Kenji de Almeida, ZANESCO, Maria Lucia; SANTOS

Claudete dos. (2021). Coordenador pedagógico como articulador das transformações na escola. In: LAMIM-GUEDES, Valdir. Metodologias ativas: diferentes abordagens e suas aplicações. São Paulo: Ed. Na Raiz, 2021. p.73-83.

MAIA, Matheus. 5 Metodologias inovadoras para criar aulas interativas e ter atenção dos seus alunos. Disponível em: www.matheus4maia.com.br Acesso em: I2/09/202I

MARTINS FILHO, Vilson; GERGES, Nina Rosa Cruz; FIALHO, Francisco Antonio Pereira. Design thinking, cognição e educação no século XXI. Revista Diálogo Educacional, i5(45), p. 579-596, 2015.

MENDES FILHO, Aldo. Utilizando o Scratch para valorizar a autoria e autonomia discente em projetos pedagógicos interdisciplinares nos conteúdos dos parâmetros curriculares nacionais (PCNs). 2016. 155p. Dissertação (Mestrado em Educação em 
área de concentração Educação) - Faculdade de Educação, Universidade Estadual de Campinas, Campinas, 2016.

MENEZES, Ebenezer Takuno de; SANTOS, Thais Helena dos. Dicionário Interativo da educação brasileira-Educabrasil. São Paulo: Midiamix Editora, 2002. Disponível em DIEB - Dicionário Interativo da Educação Brasileira - EducaBrasil Acesso em: 15/09/2021

MONTEROSA CASTRO, Ivan Javier. Diseño de un modelo de gestión estratégica de tecnologías de la información. 2010. 142p. Dissertação (Master en Dirección Estratégica en Tecnologías de la Información) - Fundación Universitaria Tecnológico de Comfenalco, Cartagena, Colombia. 2010.

MORAN, José. Metodologias ativas: alguns questionamentos. Disponível em : http://www2.eca.usp.br/moran/wp-content/uploads/2013/12/metodologias.pdf Acesso em: 08/04/2021.

MORAN, José. Metodologias ativas para uma aprendizagem mais profunda. São Paulo, Penso Ed., 2018.

MOURA, Dácio Guimarães de; BARBOSA, Eduardo F. Trabalhando com projetos: planejamento e gestão de projetos educacionais. Petrópolis, RJ: Vozes, 2017.

PAIVA, Francisco da Silva. Ensino técnico: uma breve história. Revista Húmus, 3(8), p.35-49, 2013.

PASQUALETTO, Terrimar Ignácio ; VEIT, Eliane Angela; ARAUJO, Ives Solano. Aprendizagem baseada em projetos no ensino de Física: uma revisão da literatura. Revista Brasileira de Pesquisa em Educação em Ciências, I7(2), p. 551-577, 2017 .

PEREIRA, Mauricio Gomes. A seção de resultados de um artigo científico. Epidemiologia e Serviços de Saúde, 22(2), p. 353-354, 2013. 
RAMOS, Marise. Filosofia da práxis e práticas pedagógicas de formação de trabalhadores. Trabalho \& Educação, 23(I), p. 207-218, 2014.

SANTOS, Fernanda Pereira; NUNES, Celia Maria Fernandes; VIANA, Marger da Conceição Ventura. A busca de um currículo interdisciplinar e contextualizado para ensino técnico integrado ao médio. Bolema: Boletim de Educação Matemática, 3 I(57), p. 517-536, 2017.

SANTOS, Michele Barboza dos; ROYER, Marcia Regina; DEMIZU, Fabiana Silva Botta. Metodologia de ensino por projetos: levando a prática para o ensino de ciências. EDUCERE, p.14055-14069, 2018.

SERVIÇO NACIONAL DE APRENDIZAGEM COMERCIAL (SENAC). Metodologias ativas de aprendizagem. Rio de Janeiro: SENAC, Departamento Nacional, 2018.

SILVA QUIROZ, Juan; MATURANA CASTILLO, Daniela. Una propuesta de modelo para introducir metodologías activas en educación superior. Innovación educativa (México, DF), I7(73), p. II7-I31, 2017. Disponível em: http://www.scielo.org.mx/scielo.php?script=sci_arttext\&pid=SI66526732017000100117\&lng=es \&tlng=es Acesso em: 07/04/2021.

VALENTE, José Armando. A sala de aula invertida e a possibilidade do ensino personalizado: uma experiência com a graduação em midialogia In: BACICH, Lilian; MORAN, José. Metodologias ativas para uma educação inovadora: uma abordagem teórico-prática. Porto Alegre, RS: Penso, 2018.

YAVORSKI, Rosely; SANTOS E CAMPOS, Maria Aparecida. Formação docente: a formação do professor e a influência sobre a aprendizagem do aluno. MLS Educational Research, 3(I), p:25-42, 2019. 